\title{
Bimedial rectus muscle elongation versus bimedial rectus muscle recession for the surgical treatment of large-angle infantile esotropia
}

This article was published in the following Dove Press journal:

Clinical Ophthalmology

17 October 2017

Number of times this article has been viewed

\author{
Manar A Ghali \\ Ophthalmology Department, Faculty \\ of Medicine, Zagazig University, \\ Zagazig, Egypt
}

Purpose: To compare bimedial rectus muscle recession (BMRR; 7-8 $\mathrm{mm}$ ) and bimedial rectus muscle elongation (BMRE; 6.5-9 $\mathrm{mm}$ ) for the surgical treatment of large-angle infantile esotropia (ET; $\geq 70$ prism diopters [PD]).

Patients and methods: Twenty-four patients with large-angle infantile ET were divided into 2 groups; group A $(n=12)$ underwent BMRR and group $B(n=12)$ underwent BMRE. All patients received surgery under general anesthesia and were followed for at least 24 months after surgery. The mean dose-response effect at 24 months was calculated for each patient.

Results: The mean preoperative angle of deviation was 79.16 \pm 7.64 PD (range, 70-90) in group A and $85.83 \pm 9.25$ PD (range, 70-100) in group B. The duration of surgery was $55 \%$ shorter in group A compared with group B. There were no cases of over-correction, but there were 6 cases of under-correction in group $\mathrm{A}(50 \%)$ and 2 cases of under-correction in group $\mathrm{B}(16.7 \%)$. The mean dose-response effect was $4.42 \pm 0.19 \mathrm{PD} / \mathrm{mm}$ in group A and $5.45 \pm 0.39 \mathrm{PD} / \mathrm{mm}$ in group B.

Conclusion: BMRE is more effective than BMRR for the surgical treatment of large-angle infantile ET despite a higher level of technical difficulty.

Keywords: large-angle infantile esotropia, bimedial rectus muscle recession, bimedial rectus muscle elongation, surgical treatment of infantile esotropia

\section{Introduction}

Various surgical techniques have been proposed for the treatment of infantile esotropia (ET). The traditional approach, $5 \mathrm{~mm}$ recession of the bilateral medial recti, is insufficient for ET with an angle $>50$ prism diopters (PD). ${ }^{1,2}$ Instead, bimedial rectus muscle recession (BMRR) in excess of $5 \mathrm{~mm}$ has been suggested for the correction of large-angle infantile ET. ${ }^{3,4}$

There is conflicting evidence regarding the safety and effectiveness of large BMRR; while several authors did not observe clinically significant limitation of adduction after large BMRR, ${ }^{5,6}$ others reported delayed consecutive exotropia. ${ }^{4}$ Accordingly, other procedures have been proposed to increase the effectiveness of recession, such as the Faden operation ${ }^{7,8}$ and Y-splitting recession. ${ }^{9,10}$

Also, botulinum toxin was used to augment effect of bimedial recession. ${ }^{11}$ Rectus muscle lengthening was also described using the resected part from the antagonist muscle. $^{12}$

However, bimedial rectus muscle elongation (BMRE) is a muscle weakening procedure that was first described in $1967^{13}$ and evaluated for the treatment of largeangle infantile ET in 2015. ${ }^{14}$
Ophthalmology Department, Faculty of Medicine, Zagazig University, Imam Ali Street, Zagazig 234I, Egypt

Tel +20 552320827

Email ghali_manar27@yahoo.com cc) hereby accept the Terms. Non-commercial uses of the work are permitted without any further permisision from Dove Medical Press Limited, provided the work is properly atrtibuted. For permision for commercial use of this work, please see paragraphs 4.2 and 5 of our Terms (htpps://www.dovepress.com/terms.php). 
The aim of our study was to compare the effectiveness of BMR elongation and large BMR recession $(7-8 \mathrm{~mm})$ for the treatment of large-angle ( $\geq 70 \mathrm{PD}$ ) infantile ET.

\section{Patients and methods}

Twenty-four patients with large-angle infantile ET ( $\geq 70$ PD) were recruited from the ophthalmology department of Zagazig University, Egypt, between March 2012 and June 2014. The study was approved by the Institutional Review Board of Zagazig University and all patients or guardians provided written informed consent for study participation.

Patients were excluded if they had a previous history of squint surgery or retinal surgery, a medial rectus width $<8 \mathrm{~mm}$, nervous system disease (including cerebral palsy), amblyopia, convergence excess, associated vertical deviation, or axial lengths $>23.5$ or $<21 \mathrm{~mm}$.

All patients were subjected to a full preoperative ophthalmologic examination, including slit-lamp examination of anterior segment, fundus examination, ocular motility assessment, cycloplegic refraction and spherical equivalent refractive error for all cases were reported. Glasses were prescribed for patients with significant refractive errors prior to surgery for at least 1 month; also, best corrected visual acuity was measured for cooperable patients with logarithm of minimum angle of resolution (logMAR). Deviations in primary near and distance vision were measured using alternate prism and cover test when possible, and using Krimsky method when not possible while wearing their full corrective spectacles.

Patients were randomly divided into 2 groups: group A $(n=12)$ underwent BMRR and group $B(n=12)$ underwent BMRE. All surgeries were performed under general anesthesia by the same surgeon (MA Ghali.). Amounts of recession and elongation according to the preoperative angle (based on surgeon experience and previous recommendation of Ameri et al) ${ }^{14}$ are shown in Table 1.

Table I Extent of BMR recession and elongation according to the preoperative angle

\begin{tabular}{lll}
\hline $\begin{array}{l}\text { Preoperative angle } \\
\text { of ET, PD }\end{array}$ & $\begin{array}{l}\text { Group A BMR } \\
\text { recession } \\
\text { amount, } \mathbf{~ m m}\end{array}$ & $\begin{array}{l}\text { Group B BMR } \\
\text { elongation } \\
\text { amount, } \mathbf{~ m m}\end{array}$ \\
\hline 70 & 7 & 6.5 \\
75 & 7.5 & 7 \\
80 & 8 & 7.5 \\
85 & 8 & 7.5 \\
90 & 8 & 8 \\
95 & - & 8.5 \\
100 & - & 9 \\
\hline
\end{tabular}

Abbreviations: BMR, bimedial rectus; ET, esotropia; PD, prism diopters.
In group $\mathrm{A}$, all cases underwent BMRR using conjunctival limbal incision via the anchor hang-back technique. The intermuscular membrane and check ligaments were dissected during the course of the procedure.

In group B, surgery was performed using a surgical microscope. After limbal conjunctival incision and isolation of the medial rectus muscle (Figure 1), the tendon was well dissected from the sclera and the muscle insertion width was measured to split the muscle longitudinally into 3 parts (where the width of the central section was double that of the peripheral sections; Figure 2). The length of splitting was $10-11 \mathrm{~mm}$. Then, in accordance with the angle of preoperative deviation, a muscle clamp was placed at a distance of 6.5-9 $\mathrm{mm}$ from the insertion on the peripheral sections. An incision was made just anterior to the clamp (Figure 3) and the muscle was cauterized at the clamp site. The peripheral sections remained attached to the insertion, and the wider central section was secured with 6/0 polyglactin (Vicryl) sutures (Ethicon Inc., Somerville, NJ, USA) (Figure 4). Then, the central section was detached from the insertion (Figures 5 and 6) and the distal ends of the peripheral sections were sutured to the cut end of the central section without overlapping (Figure 7). The conjunctiva was sutured with 7/0 Vicryl (Ethicon Inc.).

Patients were followed for at least 24 months after surgery. The postoperative angle of deviation for near and distance vision and any limitations in adduction were recorded at each follow-up visit. Operative success was defined as a deviation within $10 \mathrm{PD}$ of orthophoria at 24 months post-surgery.

The mean dose-response effect was calculated for close and distance vision by calculating the difference between the preoperative and postoperative angles of deviation and

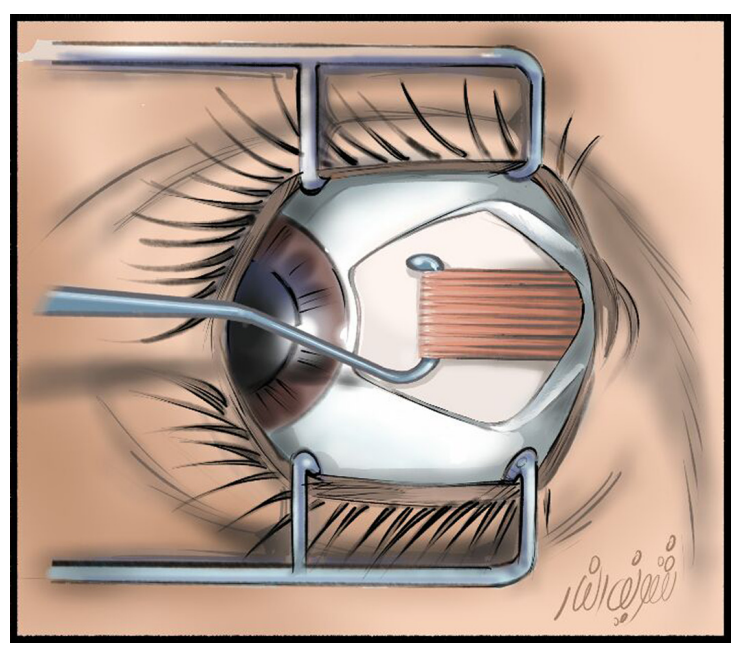

Figure I Limbal conjunctival incision and isolation of medial rectus muscle; the tendon width must be $8 \mathrm{~mm}$ or more. Courtesy of Dr Sherif El Far. 


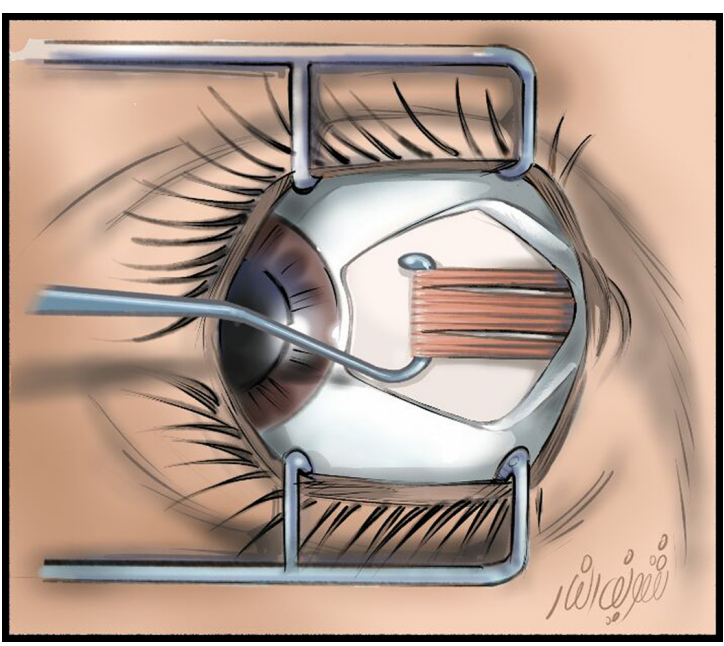

Figure 2 Splitting of the muscle longitudinally into 3 parts; the width of central section is double that of the peripheral sections. Courtesy of Dr Sherif El Far.

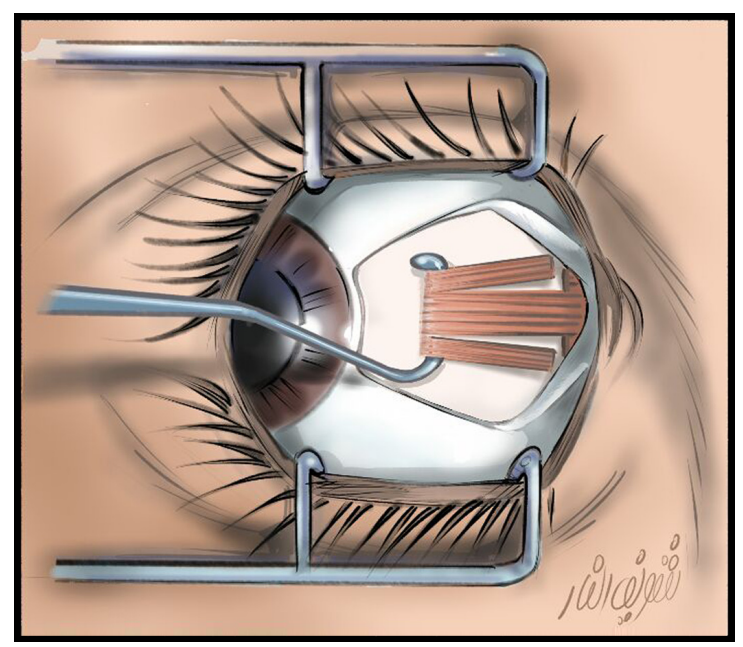

Figure 3 The peripheral sections were clamped and incised at a distance of $6.5-9 \mathrm{~mm}$ from insertion. Courtesy of Dr Sherif El Far.

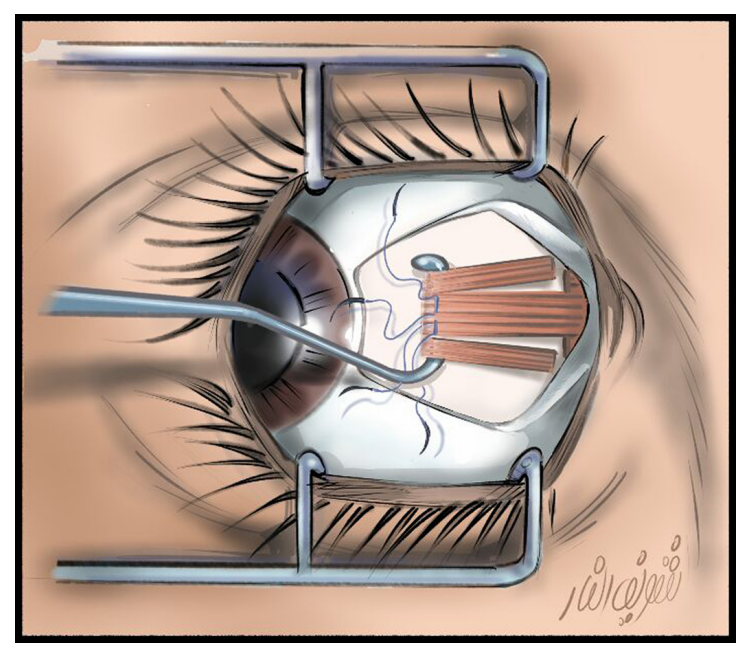

Figure 4 Securing of the wider central section with O/6 polyglactin (Vicryl) sutures (Ethicon Inc., Somerville, NJ, USA). Courtesy of Dr Sherif El Far.

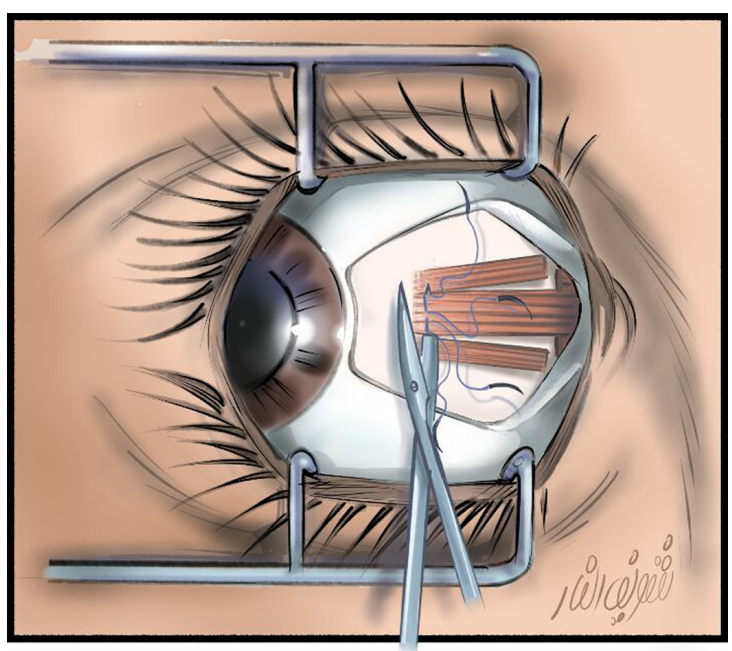

Figure 5 Cutting of the central section anterior to the sutures and in flush with the sclera. Courtesy of Dr Sherif El Far.

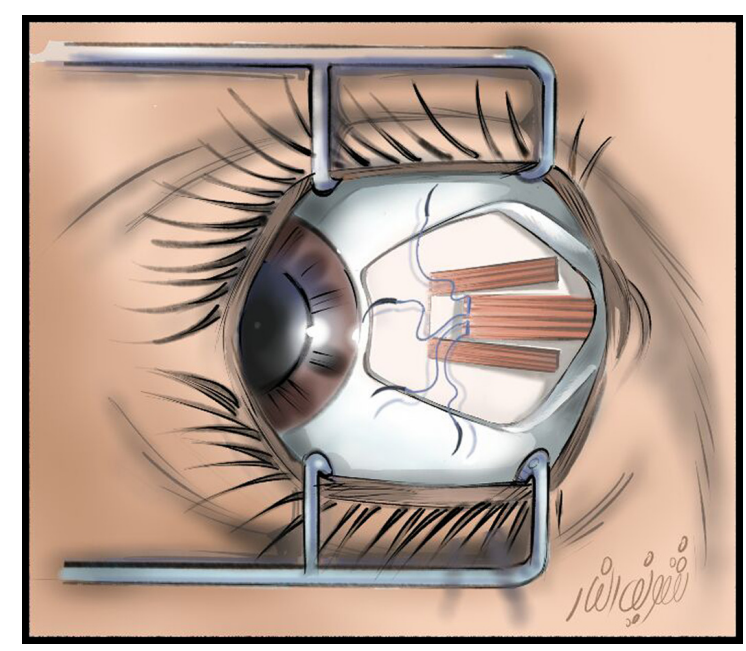

Figure 6 The central portion was detached from the insertion. Courtesy of Dr Sherif El Far.

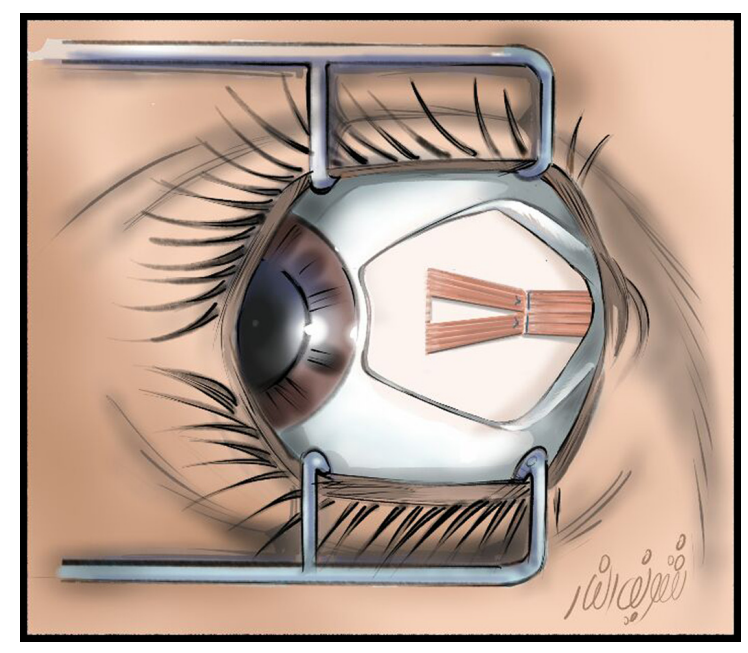

Figure 7 The distal ends of the peripheral sections were sutured to the cut end of the central portion. Courtesy of Dr Sherif El Far. 
dividing the result by the total amount of recession (group A) or elongation (group B).

All statistical analyses were performed using SPSS version 20 software (SPSS Inc., Chicago, IL, USA). Data were expressed as the mean \pm SD unless otherwise specified. Student's $t$-test was done for assessing the statistical significance of the difference between the 2 groups. $P<0.05$ was the threshold for statistical significance.

\section{Results}

In group $\mathrm{A}$, the mean age was $9.92 \pm 7.5$ years (range, 2-25 years), the refractive error spherical equivalent was $-1.06 \pm 2.77$ and best corrected visual acuity (logMAR) was $0.22 \pm 0.12$. The mean preoperative angle of deviation was 79.16 $\pm 7.64 \mathrm{PD}$ (range, 70-90 PD). In group B, the mean age was $11.17 \pm 10.53$ years (range, $2-31$ years), the refractive error spherical equivalent was $-1.33 \pm 2.49$ and best corrected visual acuity $(\log M A R)$ was $0.23 \pm 0.18$. The mean preoperative angle of deviation was $85.83 \pm 9.25$ PD (range, 70-100 PD). The mean preoperative angle of deviation was significantly higher in group B compared with group A $(P=0.013)$, while no significant statistical difference was found between both groups for other preoperative data.

The mean duration of surgery was $27.5 \pm 1.0 \mathrm{~min}$ in group A and 50 \pm 12.5 min in group B; accordingly, BMRR took 55\% less time than BMRE. The medial rectus muscle insertion width was not statistically different between groups, with a mean width of $9.38 \pm 0.64 \mathrm{~mm}$ in group A and $9.33 \pm 0.62 \mathrm{~mm}$ in group B. Additionally, there was no significant difference between the total amount of recession in group A (15.25 $\pm 0.87 \mathrm{~mm})$ and the total amount of elongation in group B $(15.42 \pm 1.51 \mathrm{~mm})$.

At 24 months post-surgery, the mean postoperative angle of deviation was significantly lower in group B compared with group A $(0.33 \pm 4.99$ PD versus $11.33 \pm 6.02 \mathrm{PD}$, respectively; $P=0.002$ ). The achieved correction and dose-response effect were also higher in group B compared with group A

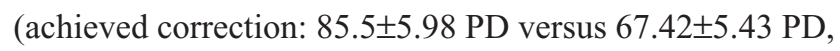
respectively; dose-response effect: $5.45 \pm 0.39 \mathrm{PD} / \mathrm{mm}$ versus 4.42 $\pm 0.19 \mathrm{PD} / \mathrm{mm}$, respectively; both $P=0.00$ ) (Table 2).

No intraoperative complications such as slipped or lost muscles were reported in either group. In group A, there were 2 cases of postoperative adduction limitation at 6 months post-surgery that were improved by 24 months post-surgery. There were no reported cases of adduction limitation in group B.

The success rate in group A was $50 \%$, with 6 cases of under-correction that were subsequently treated with 1- or 2-muscle resection in accordance with the residual angle of deviation. The success rate in group B was $83 \%$, with 2 cases of under-correction that were treated with BMRR in accordance with the residual angle of deviation.

\section{Discussion}

The present study reveals that BMRE was more effective than BMRR for the surgical treatment of large-angle infantile ET in a cohort of 24 patients. The management of infantile ET has evolved in recent years, yet the ideal method for surgical treatment remains controversial. Bilateral recession of medial rectus muscle for the treatment of large-angle infantile ET ( $\geq 60$ PD) has been reported with variable success $(60 \%-91 \%) .{ }^{15,16}$ In this study, the success rate of BMRR was $50 \%$; the difference between this value and that reported in previous studies may have been due to a larger preoperative angle (70-90 PD) in our study.

Following large recession ( $>7 \mathrm{~mm}$ ), some authors have reported delayed consecutive exotropia ${ }^{4}$ whereas others have indicated clinically nonsignificant adduction limitation. ${ }^{3}$ In this study, BMRR produced neither adduction limitation nor delayed consecutive exotropia at 24 months post-surgery. Future studies should examine the incidence of these complications over a longer follow-up period.

Table 2 Between-group comparisons

\begin{tabular}{|c|c|c|c|c|}
\hline & $\begin{array}{l}\text { Group A } \\
(n=12)\end{array}$ & $\begin{array}{l}\text { Group B } \\
(n=12)\end{array}$ & $\begin{array}{l}\text { Student's } \\
t \text {-test }\end{array}$ & $P$-value \\
\hline Age & $9.92 \pm 7.5$ years & $1 \mathrm{I} .17 \pm 10.53$ years & 0.726 & 0.476 \\
\hline Preoperative angle of deviation & $79.16 \pm 7.64 \mathrm{PD}$ & $85.83 \pm 9.25 \mathrm{PD}$ & 2.7 & $0.013^{*}$ \\
\hline Medial rectus muscle insertion width & $9.38 \pm 0.64 \mathrm{~mm}$ & $9.33 \pm 62 \mathrm{~mm}$ & 0.394 & 0.697 \\
\hline Total amount of recession or elongation & $15.25 \pm 0.87 \mathrm{~mm}$ & $15.42 \pm 1.51 \mathrm{~mm}$ & 1.3 & 0.196 \\
\hline Postoperative angle of deviation ( 24 months) & $1 \mathrm{I} .33 \pm 6.02 \mathrm{PD}$ & $0.33 \pm 4.99 \mathrm{PD}$ & 3.5 & $0.002 *$ \\
\hline Achieved correction & $67.42 \pm 5.43 \mathrm{PD}$ & $85.5 \pm 5.98 \mathrm{PD}$ & 7.7 & $0.000 *$ \\
\hline Dose-response effect & $4.42 \pm 0.19 \mathrm{PD} / \mathrm{mm}$ & $5.45 \pm 0.39 \mathrm{PD} / \mathrm{mm}$ & 7.95 & $0.00 *$ \\
\hline
\end{tabular}

Note: *Statistically significant.

Abbreviation: PD, prism diopters. 
In our study, the achieved correction after BMRE $(85.5 \pm 5.98$ PD) was significantly better than that after BMRR, and was larger than that previously reported for BMRE by Ameri et al (76.45 \pm 10.11 PD). ${ }^{14}$ The improved effectiveness of our procedure might have been due to the fact that we did not take the middle section sutures $1.5 \mathrm{~mm}$ posterior to the insertion, but instead made them flush with the insertion to increase the effect of elongation. Additionally, patients who received BMRE in our study had a smaller preoperative angle of deviation (85.83 $\pm 9.25 \mathrm{PD})$ and were followed up for a longer period (24 months) compared with patients in the study by Ameri et al (94.1 19.33 PD). Moreover, the mean dose-response effect of BMRE in our study $(5.45 \pm 0.39 \mathrm{PD} / \mathrm{mm})$ was comparable with that reported by Ameri et al $(5.53 \pm 0.67 \mathrm{PD} / \mathrm{mm})^{14}$ and notably better than that reported by Sood et al. ${ }^{13}$

The success rate of BMRE ( $83 \%)$ was higher than that of BMRR $(50 \%)$ in our study and higher than that reported for BMRE by Ameri et $\mathrm{al}^{14}(70 \%)$. It is notable that the success rate of BMRE in our study was also better than that reported for 3 horizontal muscle surgeries $(62.4 \%) .{ }^{17}$ These data suggest that BMRE is the most effective surgical treatment method for large-angle infantile ET.

The present study had some limitations, including the small sample size and the significant difference found between the preoperative angle of deviation of both groups. Our findings should be confirmed in a future large-scale study that employs a longer follow-up period. Furthermore, the effect of elongation on other muscles must be determined in future studies.

In conclusion, BMRE is an effective although technically demanding method for the surgical treatment of large-angle infantile ET. Although the BMRE procedure is time-consuming and has a learning curve for surgeons, it is generally safe as there is no risk of scleral perforation.

\section{Disclosure}

The author reports no conflicts of interest in this work.

\section{References}

1. Ing MR, Costen Bader FE, Parks MM, Albert DG. Early surgery for congenital esotropia. Am J Ophthalmol. 1966;61:1419-1427.

2. Scott WE, Reese PD, Hirsh CR, Habetich CA. Surgery for large angle congenital esotropia. Arch Ophthalmol. 1986;104(3):376-377.

3. Damanakis AG, Arvanitis PG, Ladas ID, Theodossiadis GP. $8 \mathrm{~mm}$ bimedial rectus recession in infantile esotropia of $80-90$ prism diopters. Br J Ophthalmol. 1994;78(11):842-844.

4. Stager DR, Weakley DR. Delayed consecutive exotropia following $7 \mathrm{~mm}$ bilateral medial rectus recession for infantile esotropia. AAPOS Meeting; April 18-22, 1993; Palm Springs, CA.

5. Hess JB, Calhoun JH. A new rationale for the management of large angle esotropia. J Pediatr Ophthalmol Strabismus. 1979;16(6):345-348.

6. Weakley DR Jr, Stager DR, Everett ME. Seven millimeter bilateral medial rectus recession in infantile esotropia. J Pediatr Ophthalmol Strabismus. 1991;28(2):113-115.

7. Spiritus M. Large bimedial rectus recession versus bimedial posterior fixation with additional rectus recessions. Trans 19th Meeting ESA; June 59-64; 1991; Crete.

8. Castanera AM. Length-tension diagrams of medial rectus muscles after Cuppers' Faden operation. Surgical assessment of reversibility of posterior fixation sutures. Ophthalmologica. 1989;198:46-52.

9. Hocrantner R, Priglinger S, Haslwanter T. Reduction of ocular muscle torque by splitting of the rectus muscle II; technique and results. $\mathrm{Br} \mathrm{J}$ Ophthalmol. 2004;88(11):1409-1413.

10. Badawi N, Hegazy K. Comparative study of Y split recession versus bilateral medial rectus recession for wurgical management of infantile esotropia. Clin Ophthalmol. 2004;8:1039-1045.

11. Lueder GT, Galli M, Tychsen L, Yildirim C, Pegado V. Long-term results of botulinum toxin-augmented medial rectus recessions for largeangle infantile esotropia. Am J Ophthalmol. 2012;153(3):560-563.

12. Amitava AK, Goswami AK, Mishra A. Large-angle strabismus and primary true muscle transplantation. J Pediatr Ophthalmol Strabismus. 2005;42(4):211-215.

13. Sood GC, Malik SR, Gunguli G, Ghawdhary. Lengthening of rectus muscles in strabismus surgery: with a description of a new muscle clamp. Br J Ophthalmol. 1967;51(11):788-790.

14. Ameri A, Akbari MR, Keshtkar Jaafari AR, et al. Medial rectus muscle elongation, a technique to treat very large angle esotropia. Graefes Arch Clin Exp Ophthalmol. 2015;253(7):1005-1011.

15. Szmyd SM, Nelson LB, Calhoun JH, Spratt C. Large bimedial rectus recessions in congenital esotropia. Br J Ophthalmol. 1985;69(4): 271-274.

16. Castro PD, Pedraso A, Hernandez L Naranjo RM, Mendez TJ, Arias A. Results of surgery for congenital esotropia. MEDICC Rev. 2011;13(1): $18-22$.

17. Chatzistefanou K, Ladas ID, Droutsas KD, Koutsandrea C, ChimonidouE. Three horizontal muscle surgery for large angle infantile or presumed infantile esotropia long term motor outcomes. JAMA Ophthalmol. 2013;131(8):1041-1048.
Clinical Ophthalmology

\section{Publish your work in this journal}

Clinical Ophthalmology is an international, peer-reviewed journal covering all subspecialties within ophthalmology. Key topics include: Optometry; Visual science; Pharmacology and drug therapy in eye diseases; Basic Sciences; Primary and Secondary eye care; Patient Safety and Quality of Care Improvements. This journal is indexed on Submit your manuscript here: http://www.dovepress.com/clinical-ophthalmology-journal

\section{Dovepress}

PubMed Central and CAS, and is the official journal of The Society of Clinical Ophthalmology (SCO). The manuscript management system is completely online and includes a very quick and fair peer-review system, which is all easy to use. Visit http://www.dovepress.com/ testimonials.php to read real quotes from published authors. 